This is the peer reviewed version of the following article: Fortea, J. I.; Zipprich, A.; Fernandez-Mena, C.; Puerto, M.; Bosoi, C. R.; Almagro, J.; Hollenbach, M.; Bañares, J.; Rodríguez-Sánchez, B.; Cercenado, E.; Clément, M.-A.; Rose, C. F.; Bañares, R.; Vaquero, J. \& Ripoll, C. Enoxaparin does not ameliorate liver fibrosis or portal hypertension in rats with advanced cirrhosis. Liver international 2018, $38,102-112$, which has been published in final form at 10.1111/liv.13510. This article may be used for non-commercial purposes in accordance with Wiley Terms and Conditions for Use of Self-Archived Versions.

\title{
ENOXAPARIN DOES NOT AMELIORATE LIVER FIBROSIS OR PORTAL HYPERTENSION IN RATS WITH ADVANCED CIRRHOSIS
}

\section{José I. Fortea1,2, Alexander Zipprich3, Carolina Fernandez-Mena1,2, Marta Puerto1,2,4, Cristina R. Bosoi5, Jorge Almagro1,2, Marcus Hollenbach3, Juan Bañares1,2, Belén Rodríguez-Sánchez2,6,7, Emilia Cercenado2,6, Marc-André Clément5, Christopher F. Rose5, Rafael Bañares1,2,4,8, Javier Vaquero1,2,4, Cristina Ripoll1,2,3,4,}

1. Laboratorio Investigación Hepatología y Gastroenterología, HGU Gregorio Marañón, Madrid, Spain

2. Instituto Investigación Sanitaria Gregorio Marañón (IiSGM), Madrid, Spain

3. Innere Medizin I, Martin-Luther-Universität Halle-Wittenberg, Halle, Germany

4. CIBERehd, Madrid, Spain

5. Hepato-neuro laboratory, CRCHUM, Université de Montréal, Montréal, Canada

6. Microbiología Clínica y Enfermedades Infecciosas, HGU Gregorio Marañón, Madrid, Spain

7. CIBERES, Madrid, Spain

8. Facultad de Medicina, Universidad Complutense, Madrid, Spain

Correspondence Javier Vaquero, Laboratorio de Investigación en Hepatología y Gastroenterología, HGU Gregorio Marañón-IiSGM-CIBERehd, Pabellón de Medicina y Cirugía Experimental, Madrid, Spain. Email:

javier.vaquero@iisgm.com

Funding information Work funded by ISCIII-Fondos FEDER grant to CR (FIS PI11/00956). JV was supported by Ramón \& Cajal grant (R\&C2010-05838) from MINECO, and CFM by IiSGM fellowship.

\section{ABSTRACT}

Background \& Aims Recent studies suggest that heparins reduce liver fibrosis and the risk of decompensation of liver disease. Here, we evaluated the effects of enoxaparin in several experimental models of advanced cirrhosis. Methods Cirrhosis was induced in male Sprague-Dawley (SD) rats by: (i) Oral gavage with carbon tetrachloride $\left(\mathrm{CCl} 4_{\mathrm{ORAL}}\right.$ ), (ii) Bile duct ligation (BDL) and (iii) $\mathrm{CCl} 4$ inhalation $\left(\mathrm{CCl}_{\mathrm{INH}}\right)$. Rats received saline or enoxaparin s.c. (40 IU/Kg/d or $180 \mathrm{IU} / \mathrm{Kg} / \mathrm{d}$ ) following various protocols. Blood biochemical parameters, liver fibrosis, endothelium- and fibrosis-related genes, portal pressure, splenomegaly, bacterial translocation, systemic inflammation and survival were evaluated. Endothelial dysfunction was assessed by in situ bivascular liver perfusions. Results Enoxaparin did not ameliorate liver function, liver fibrosis, profibrogenic gene expression, portal hypertension, splenomegaly, ascites development and infection, serum IL-6 levels or survival in rats with CCl4 ${ }_{\mathrm{ORAL}}$ or BDL-induced cirrhosis. Contrarily, enoxaparin worsened portal pressure in BDL rats and decreased survival in $\mathrm{CCl}_{\mathrm{ORAL}}$ rats. In $\mathrm{CCl}_{\mathrm{INH}}$ rats, enoxaparin had no effects on hepatic endothelial dysfunction, except for correcting the hepatic arterial dysfunction when enoxaparin was started with the $\mathrm{CCl} 4$

Fortea, J. I.; Zipprich, A.; Fernandez-Mena, C.; Puerto, M.; Bosoi, C. R.; Almagro, J.; Hollenbach, M.; Bañares, J.; Rodríguez-Sánchez, B.; Cercenado, E.; Clément, M.-A.; Rose, C. F.; Bañares, R.; Vaquero, J. \& Ripoll, C. Enoxaparin does not ameliorate liver fibrosis or portal hypertension in rats with advanced cirrhosis. Liver international 2018, 38, 102-112 
This is the peer reviewed version of the following article: Fortea, J. I.; Zipprich, A.; Fernandez-Mena, C.; Puerto, M.; Bosoi, C. R.; Almagro, J.; Hollenbach, M.; Bañares, J.; Rodríguez-Sánchez, B.; Cercenado, E.; Clément, M.-A.; Rose, C. F.; Bañares, R.; Vaquero, J. \& Ripoll, C. Enoxaparin does not ameliorate liver fibrosis or portal hypertension in rats with advanced cirrhosis. Liver international 2018, $38,102-112$, which has been published in final form at 10.1111/liv.13510. This article may be used for non-commercial purposes in accordance with Wiley Terms and Conditions for Use of Self-Archived Versions.

exposure. In these rats, however, enoxaparin increased liver fibrosis and the absolute values of portal venous and sinusoidal resistance. Conclusions Our results do not support a role of enoxaparin for improving liver fibrosis, portal hypertension or endothelial dysfunction in active disease at advanced stages of cirrhosis. These disease-related factors and the possibility of a limited therapeutic window should be considered in future studies evaluating the use of anticoagulants in cirrhosis.

\section{ABBREVIATIONS}

- Acta2 smooth muscle alpha-2 actin

- BDL bile-duct ligation

- BW body weight

- $\mathrm{CCL} 4_{\mathrm{INH}}$ carbon tetrachloride by inhalation

- $\mathrm{CCl}_{\text {ORAL }}$ carbon tetrachloride by oral gavage

- Collal alpha-1 type I collagen

- CTRL control
- Enos or eNOS endothelial nitric-oxide synthase

- IL-6 interleukin 6

- L-NMMA $\mathrm{N}^{\mathrm{G}}$-Methyl-L-arginine acetate salt

- SD Sprague-Dawley rats

- SNAP S-Nitroso-N-acetyl-DL-penicillamine

- Timp1 TIMP metallopeptidase inhibitor 1

- Vegfa vascular endothelial growth factor A

KEY POINTS

- Anticoagulation has been proposed to have antifibrogenic effects and to attenuate portal hypertension-related complications in mild-to-moderate liver disease.

- We evaluated several doses and protocols of enoxaparin administration in three different models of advanced cirrhosis in rats.

- Enoxaparin administration failed to ameliorate liver function, liver fibrosis, profibrogenic gene expression, portal hypertension, splenomegaly, ascites development and infection, serum IL-6 levels, hepatic endothelial dysfunction or survival.

- Beneficial effects of enoxaparin may be lost or become even detrimental at late stages of advanced liver disease. The possibility of a limited therapeutic window should be considered in future studies.

\section{INTRODUCTION}

The traditional concept of cirrhosis as the terminal stage of chronic liver disease has gradually changed to its view as an entity comprising progressive phases with distinct prognosis and therapeutic opportunities, which include the use of anticoagulants. 1 Indeed, cirrhosis is no longer considered a bleeding disorder, but rather a disease with a delicate equilibrium between prothrombotic and prohaemorrhagic profiles that may be unbalanced towards the former, leading to thrombotic manifestations such as portal vein thrombosis. 2 Importantly, prothrombotic states may also contribute to liver fibrosis by generating thrombi in the hepatic microcirculation that cause parenchymal extinction and by activating hepatic stellate cells via protease-activated receptors. 3, 4 Consequently, the use of enoxaparin at prophylactic doses (4000 IU/day for 48 weeks) vs no treatment was recently tested by Villa et al. in 70 patients with cirrhosis (Child B7-C10).5 Patients receiving enoxaparin had

Fortea, J. I.; Zipprich, A.; Fernandez-Mena, C.; Puerto, M.; Bosoi, C. R.; Almagro, J.; Hollenbach, M.; Bañares, J.; Rodríguez-Sánchez, B.; Cercenado, E.; Clément, M.-A.; Rose, C. F.; Bañares, R.; Vaquero, J. \& Ripoll, C. Enoxaparin does not ameliorate liver fibrosis or portal hypertension in rats with advanced cirrhosis. Liver international 2018, 38, 102-112 
This is the peer reviewed version of the following article: Fortea, J. I.; Zipprich, A.; Fernandez-Mena, C.; Puerto, M.; Bosoi, C. R.; Almagro, J.; Hollenbach, M.; Bañares, J.; Rodríguez-Sánchez, B.; Cercenado, E.; Clément, M.-A.; Rose, C. F.; Bañares, R.; Vaquero, J. \& Ripoll, C. Enoxaparin does not ameliorate liver fibrosis or portal hypertension in rats with advanced cirrhosis. Liver international 2018, $38,102-112$, which has been published in final form at 10.1111/liv.13510. This article may be used for non-commercial purposes in accordance with Wiley Terms and Conditions for Use of Self-Archived Versions.

lower incidence of portal vein thrombosis and a sustained decrease in decompensations that exceeded the expected from the reduction in portal vein thrombosis. The authors hinted at an enoxaparin-induced improvement of intestinal barrier function and reduced bacterial translocation as a potential mechanism.

Low molecular weight heparins have mechanisms besides their anticoagulant effect that may be beneficial in cirrhosis. Several studies have reported anti-inflammatory 6 and anti-angiogenic effects, 7 and improvements of endothelial cell function by low molecular weight heparins. 8 In addition, antifibrotic effects of heparins were suggested in patients with chronic hepatitis B.9 Low molecular weight heparins have been reported to reduce liver fibrosis, stellate cell activation, and hepatocyte apoptosis/necrosis in toxic and surgical rodent models of cirrhosis.10-13 Recently, remarkable attenuations of stellate cell activation and fibrin sinusoidal deposition together with reductions in liver fibrosis and portal hypertension were described in cirrhotic rats treated with enoxaparin.14 Importantly, all prior experimental studies involved models of early fibrosis or cirrhosis regression, and evaluated only high enoxaparin doses ( $\geq 180 \mathrm{IU} / \mathrm{Kg} /$ day) in contrast to the prophylactic dose $(40-60 \mathrm{IU} / \mathrm{Kg} /$ day $)$ used clinically.5, 9 In addition, mechanisms of enoxaparin other than direct antifibrogenic effects or effects on the intestinal epithelial barrier remain unexplored in cirrhosis.

Here, we evaluated the effects of enoxaparin on liver fibrosis, portal hypertension and vascular endothelial cell dysfunction using diverse protocols of enoxaparin administration and several experimental models of advanced cirrhosis in rats.

MATERIAL AND METHODS

All experiments were performed in male Sprague-Dawley (SD) rats (Charles River Laboratories). The studies were approved by the Comité de Ética en Experimentación Animal of HGU Gregorio Marañón, the Institutional Animal Protection Committee of CRCHUM and the Landesverwaltungsamt SachsenAnhalt of Martin-Luther-Universität Halle-Wittenberg. Rats were housed in temperature- and humidity-controlled rooms, with a 12:12 h light:dark cycle, free access to standard chow and water and a 7-10 days acclimatization period. We used several regimes of enoxaparin administration (Clexane prefilled syringes ${ }^{\circledR}$, SANOFI-AVENTIS France) and three experimental models of cirrhosis (Figure 1A).

Fortea, J. I.; Zipprich, A.; Fernandez-Mena, C.; Puerto, M.; Bosoi, C. R.; Almagro, J.; Hollenbach, M.; Bañares, J.; Rodríguez-Sánchez, B.; Cercenado, E.; Clément, M.-A.; Rose, C. F.; Bañares, R.; Vaquero, J. \& Ripoll, C. Enoxaparin does not ameliorate liver fibrosis or portal hypertension in rats with advanced cirrhosis. Liver international 2018, 38, 102-112 
This is the peer reviewed version of the following article: Fortea, J. I.; Zipprich, A.; Fernandez-Mena, C.; Puerto, M.; Bosoi, C. R.; Almagro, J.; Hollenbach, M.; Bañares, J.; Rodríguez-Sánchez, B.; Cercenado, E.; Clément, M.-A.; Rose, C. F.; Bañares, R.; Vaquero, J. $\&$ Ripoll, C. Enoxaparin does not ameliorate liver fibrosis or portal hypertension in rats with advanced cirrhosis. Liver international 2018, $38,102-112$, which has been published in final form at 10.1111/liv.13510. This article may be used for non-commercial purposes in accordance with Wiley Terms and Conditions for Use of Self-Archived Versions.

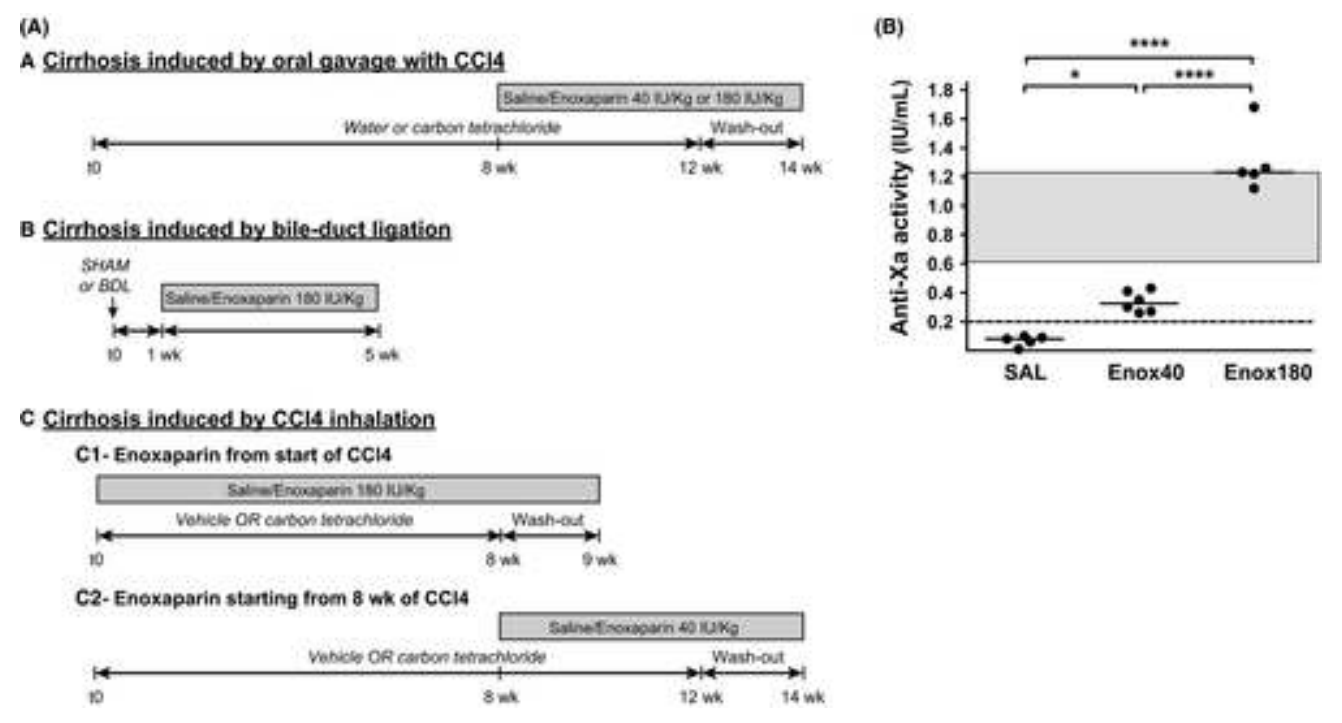

Figure 1 (A) Schematic of experimental design and protocols of enoxaparin administration. Abbreviations: BDL, bile-duct ligation; CCl4, carbon tetrachloride; wk, week. (B) Quantification of anti-Xa activity in arterial blood collected 30 minutes after an intravenous injection of sterile $0.9 \%$ saline (SAL), enoxaparin $40 \mathrm{IU} / \mathrm{Kg}$ (Enox40), or enoxaparin $180 \mathrm{IU} / \mathrm{Kg}$ (Enox 180) in rats. The dots and group lines represent the value from individual rats and the median, respectively. The dashed line represents the lower limit of the prophylactic range of enoxaparin, and the darker area represents its therapeutic anticoagulation range. $* P<.05, * * * * P<.0001$ (ANOVA with Tukey's post hoc tests)

\section{EXPERIMENT A. CIRRHOSIS INDUCED BY ADMINISTRATION OF CCL4 BY ORAL GAVAGE}

Experiments were performed at the HGU Gregorio Marañón (Madrid, Spain). Cirrhosis was induced in male SD rats (130-200 g bw) by the administration of CCl4 based on the protocol by Regimbeau et al.15 Briefly, phenobarbital $(0.35 \mathrm{~g} / \mathrm{l})$ was added to the drinking water 2 weeks before starting $\mathrm{CCl} 4$ administration (99.9\% pure, Sigma-Aldrich) until the day of euthanasia. CCl4 was administered biweekly (Monday and Friday) by oral gavage for 12 weeks, with the dose adjusted to the body weight (BW) of the rat on that same day. Rats in control groups (CTRL) received $0.5 \mathrm{~mL}$ of water instead of CCl4. All rats received enoxaparin (40 IU/Kg/day s.c. [Enox40 groups] or $180 \mathrm{IU} / \mathrm{Kg} /$ day s.c. [Enox180 groups]) or saline (Sal, $0.5 \mathrm{~mL} /$ day s.c.) from the 8th week of CCl4 administration until the end of experiments (Figure 1A). We studied the following experimental groups: CTRL+Sal $(n=5)$, CTRL+Enox40 ( $n=5)$, CTRL+Enox180 ( $n=3), \mathrm{CCl}_{\mathrm{ORAL}}+\operatorname{Sal}(\mathrm{n}=15), \mathrm{CCl}_{\mathrm{ORAL}}+\operatorname{Enox} 40(\mathrm{n}=15)$, and $\mathrm{CCl} 4_{\mathrm{ORAL}}+$ Enox180 $(\mathrm{n}=10)$. Three rats in the $\mathrm{CCl} 4_{\mathrm{ORAL}}+\mathrm{Sal}$ and $\mathrm{CCl} 4_{\mathrm{ORAL}}+$ Enox180 groups, and two $\mathrm{CCl}_{\mathrm{ORAL}}+$ Enox40 rats were excluded owing to death related to technical complications of oral gavage. A haemodynamic study was performed 2 weeks after the last CCl4 dose.

\section{EXPERIMENT B. CIRRHOSIS INDUCED BY COMMON BILE-DUCT LIGATION (BDL)}

Experiments were performed at the Hepato-Neuro Laboratory of CRCHUM-Université de Montréal (Montreal, QC, Canada). Male SD rats (250 g bw) underwent BDL or sham surgery as previously

Fortea, J. I.; Zipprich, A.; Fernandez-Mena, C.; Puerto, M.; Bosoi, C. R.; Almagro, J.; Hollenbach, M.; Bañares, J.; Rodríguez-Sánchez, B.; Cercenado, E.; Clément, M.-A.; Rose, C. F.; Bañares, R.; Vaquero, J. \& Ripoll, C. Enoxaparin does not ameliorate liver fibrosis or portal hypertension in rats with advanced cirrhosis. Liver international 2018, 38, 102-112 
This is the peer reviewed version of the following article: Fortea, J. I.; Zipprich, A.; Fernandez-Mena, C.; Puerto, M.; Bosoi, C. R.; Almagro, J.; Hollenbach, M.; Bañares, J.; Rodríguez-Sánchez, B.; Cercenado, E.; Clément, M.-A.; Rose, C. F.; Bañares, R.; Vaquero, J. \& Ripoll, C. Enoxaparin does not ameliorate liver fibrosis or portal hypertension in rats with advanced cirrhosis. Liver international 2018, $38,102-112$, which has been published in final form at 10.1111/liv.13510. This article may be used for non-commercial purposes in accordance with Wiley Terms and Conditions for Use of Self-Archived Versions.

described.16 Briefly, the abdomen was opened, formalin $(1 \mu \mathrm{L} / \mathrm{mg})$ was injected intracholedochally, and the common bile duct was ligated and cut. In the Sham group, the common bile duct was only manipulated. One week later, enoxaparin $(180 \mathrm{IU} / \mathrm{Kg} /$ day $)$ or saline $(0.5 \mathrm{~mL} /$ day $)$ was given s.c. for 4 weeks (Figure 1A). Four groups were studied: Sham+Sal $(n=6)$, Sham+Enox180 $(n=6), B D L+S a l$ $(\mathrm{n}=7)$ and BDL+Enox180 $(\mathrm{n}=10)$. Rats underwent a haemodynamic study on the 5th week.

\section{EXPERIMENT C. CIRRHOSIS INDUCED BY INHALATION OF CCL4}

Experiments were performed at Martin-Luther-Universität Halle-Wittenberg (Halle, Germany). Male $\mathrm{SD}$ rats (75-100 g bw) were exposed to gaseous CCl4 three times a week in a fume hood for 8 or 12 weeks (Figure 1A). Phenobarbital $(0.35 \mathrm{~g} / \mathrm{l})$ was added to the drinking water as previously described.17 In experiment C.1, saline $\left(0.5 \mathrm{~mL} /\right.$ day s.c, $\mathrm{CCl}_{\mathrm{INH}}+$ Sal group, $\left.\mathrm{n}=22\right)$ or enoxaparin $\left(180 \mathrm{IU} / \mathrm{Kg} /\right.$ day s.c, $\mathrm{CCl} 4_{\mathrm{INH}}+$ Enox180 group, $\left.\mathrm{n}=29\right)$ was administered from the first day of $\mathrm{CCl} 4$ exposure until the performance of the liver perfusions in the 8th week of treatment. In experiment C.2, saline $(0.5 \mathrm{~mL} /$ day s.c, $\mathrm{n}=18)$ or enoxaparin $\left(40 \mathrm{IU} / \mathrm{Kg} /\right.$ day s.c, $\mathrm{CCl} 4_{\mathrm{INH}}+\mathrm{Enox} 40$ group, $\left.\mathrm{n}=20\right)$ was injected from the 8th week of $\mathrm{CCl} 4$ administration until the performance of the in situ liver perfusions.

\section{MEASUREMENT OF ANTI-XA ACTIVITY}

SD rats ( $\mathrm{n}=5$-6/group) were i.v. injected $0.9 \%$ saline, enoxaparin $40 \mathrm{IU} / \mathrm{Kg}$ or enoxaparin $180 \mathrm{IU} / \mathrm{Kg}$ under sevoflurane anaesthesia. Thirty minutes later, blood from the aorta was collected in citratecontaining tubes. Anti-Xa activity was measured using Liquid Anti-Xa (Cat\#20302600, HemosIL ${ }^{\circledR}$ Instrumentation Laboratory, Germany).

\section{HAEMATOLOGICAL AND BIOCHEMICAL BLOOD TESTS}

Arterial blood was obtained just before euthanasia. Blood cell counts, arterial blood gases, coagulation and biochemical parameters were measured in automated analysers. Serum aliquots were stored at $-80^{\circ} \mathrm{C}$.

\section{MICROBIOLOGICAL STUDY OF ASCITES}

An ascites sample obtained under sterile conditions immediately after opening the abdomen was inoculated into thioglycolate-containing tubes. After a 3-day incubation at $37^{\circ} \mathrm{C}$, the tubes were examined for bacterial growth.

\section{CIRCULATING CONCENTRATION OF INTERLEUKIN (IL)-6}

The concentration of IL- 6 was measured in serum from arterial blood using a commercially available rat IL-6 ELISA kit (BD Biosciences).

Fortea, J. I.; Zipprich, A.; Fernandez-Mena, C.; Puerto, M.; Bosoi, C. R.; Almagro, J.; Hollenbach, M.; Bañares, J.; Rodríguez-Sánchez, B.; Cercenado, E.; Clément, M.-A.; Rose, C. F.; Bañares, R.; Vaquero, J. \& Ripoll, C. Enoxaparin does not ameliorate liver fibrosis or portal hypertension in rats with advanced cirrhosis. Liver international 2018, 38, 102-112 
This is the peer reviewed version of the following article: Fortea, J. I.; Zipprich, A.; Fernandez-Mena, C.; Puerto, M.; Bosoi, C. R.; Almagro, J.; Hollenbach, M.; Bañares, J.; Rodríguez-Sánchez, B.; Cercenado, E.; Clément, M.-A.; Rose, C. F.; Bañares, R.; Vaquero, J. \& Ripoll, C. Enoxaparin does not ameliorate liver fibrosis or portal hypertension in rats with advanced cirrhosis. Liver international 2018, $38,102-112$, which has been published in final form at 10.1111/liv.13510. This article may be used for non-commercial purposes in accordance with Wiley Terms and Conditions for Use of Self-Archived Versions.

HAEMODYNAMIC STUDY, HISTOLOGY AND QUANTIFICATION OF FIBROSIS, HEPATIC MRNA AND PROTEIN EXPRESSION OF FIBROSIS-AND ENDOTHELIUM-RELATED GENES

See Supporting Information for detailed descriptions.

EX VIVO ASSESSMENT OF MICROCIRCULATORY DYSFUNCTION OF HEPATIC VASCULAR BED

The perfusion experiments were done 6-10 days after the last CCl4 dose using two different set-ups, consisting of a single portal vein perfusion and a bivascular liver perfusion, as previously described.17, 18 See Supporting Information for further details.

\section{STATISTICAL ANALYSIS}

Quantitative variables were expressed as mean \pm SEM or median[interquartile range], and qualitative variables as proportions. For each model, all control rats (receiving water instead of CCl4, or sham surgery instead of BDL) were pooled to gain statistical power and to comply with the three Rs principle. Control rats receiving enoxaparin remained identified by distinct symbols in graphs. Analyses without pooling only showed minor changes without interference on the comparisons between cirrhotic rats treated or not-treated with enoxaparin. Differences between groups were assessed by ANOVA with Tukey's post hoc tests or by the Kruskal-Wallis test with Dunn's tests. Supplementary Table 1 in Supporting Information contains the $P$ values corresponding to post hoc comparisons between cirrhotic rats treated or not treated with enoxaparin. Proportions were compared with the Fisher's exact test. Survival was analysed using the Log-rank Test, applying the Bonferroni's correction of $p$ for post hoc multiple comparisons $(0.05 / 6=0.0083)$. The liver perfusion experiments were analysed by General Linear Model for Repeated Measurements, followed by LSD post hoc test when comparisons included more than two groups. $P<.05$ was statistically significant. Software used was Prism v6.00 (GraphPad-Software, San Diego, CA, USA) and IBM SPSS-Statistics v21 (IBM Corp, Armonk, NY, USA).

\section{RESULTS}

ENOXAPARIN DOSES AND ANTI-XA ACTIVITY

The doses of enoxaparin used in this study adequately targeted the prophylactic $(0.2$ to $0.5 \mathrm{IU} / \mathrm{mL})$ and therapeutic $(0.5$ to $1.2 \mathrm{IU} / \mathrm{mL})$ ranges of anti-Xa activity (Figure 1B).

\section{SURVIVAL}

In the oral CCl4 model, the survival in the Pooled Controls, the $\mathrm{CCl}_{\mathrm{ORAL}}+\mathrm{Sal}$, the $\mathrm{CCl}_{\mathrm{ORAL}}+$ Enox 40 and the $\mathrm{CCl}_{\mathrm{ORAL}}+$ Enox 180 groups was, respectively, $100 \%, 82.5 \%, 67.7 \%$ and $38.1 \%$ (Log-rank test $P=.02$; Pooled CTRLs vs CCl4 ${ }_{\text {ORAL }}+$ Enox 180 group $P=.002$, Figure 2$)$. Only two

Fortea, J. I.; Zipprich, A.; Fernandez-Mena, C.; Puerto, M.; Bosoi, C. R.; Almagro, J.; Hollenbach, M.; Bañares, J.; Rodríguez-Sánchez, B.; Cercenado, E.; Clément, M.-A.; Rose, C. F.; Bañares, R.; Vaquero, J. \& Ripoll, C. Enoxaparin does not ameliorate liver fibrosis or portal hypertension in rats with advanced cirrhosis. Liver international 2018, 38, 102-112 
This is the peer reviewed version of the following article: Fortea, J. I.; Zipprich, A.; Fernandez-Mena, C.; Puerto, M.; Bosoi, C. R.; Almagro, J.; Hollenbach, M.; Bañares, J.; Rodríguez-Sánchez, B.; Cercenado, E.; Clément, M.-A.; Rose, C. F.; Bañares, R.; Vaquero, J. \& Ripoll, C. Enoxaparin does not ameliorate liver fibrosis or portal hypertension in rats with advanced cirrhosis. Liver international 2018, $38,102-112$, which has been published in final form at 10.1111/liv.13510. This article may be used for non-commercial purposes in accordance with Wiley Terms and Conditions for Use of Self-Archived Versions.

$\mathrm{CCl} 4_{\mathrm{ORAL}}+$ Enox 180 rats were alive at the end of the 12-week protocol and, therefore, this group was not included in further analyses. Mortality in rats receiving CCl4 was generally preceded by weight loss and progressive deterioration related to liver disease, with no evidence of bleeding in any group.

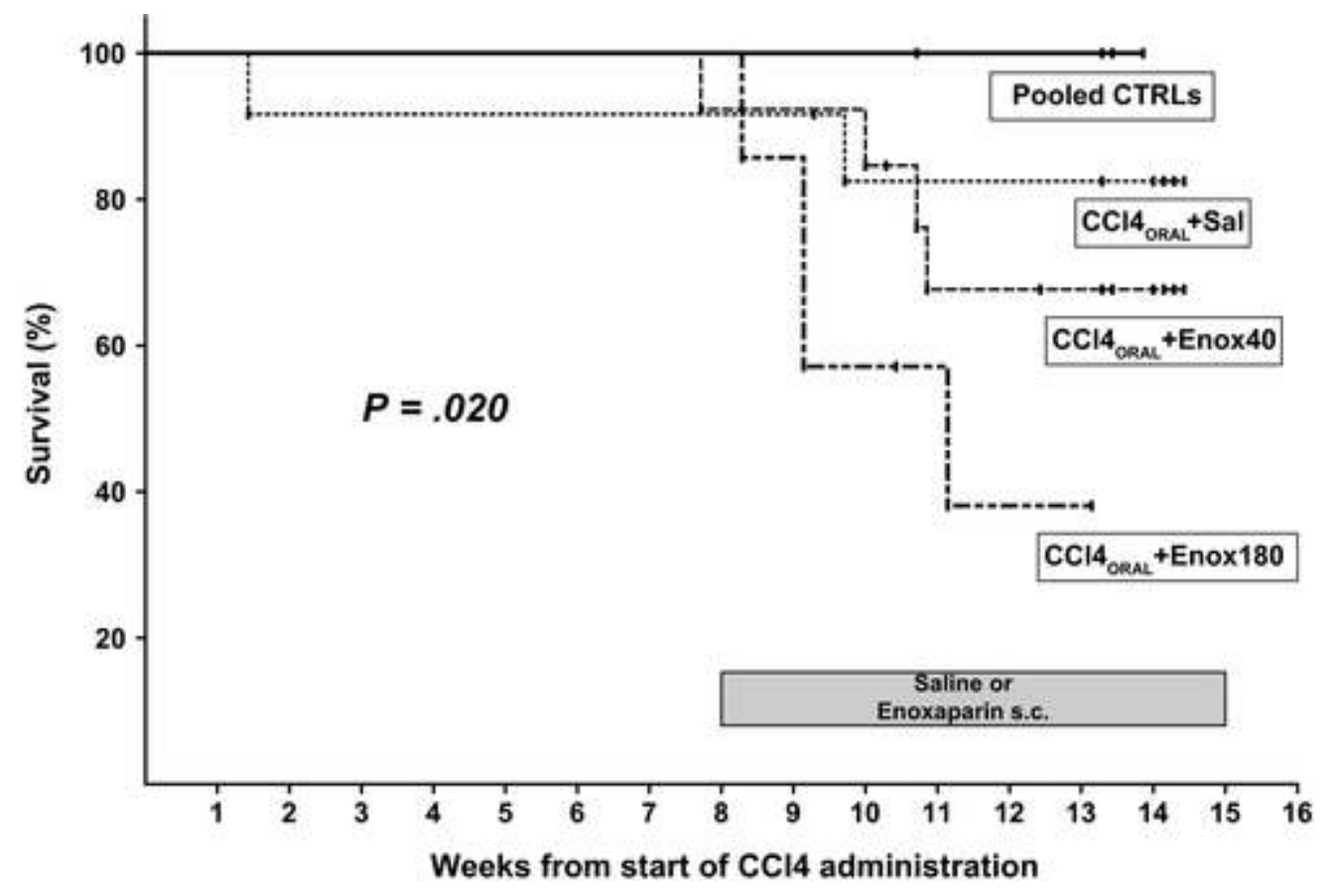

Figure 2 Effect of enoxaparin on survival of rats with cirrhosis induced by $\mathrm{CCl} 4$ administered by oral gavage. The groups of rats receiving water instead of $\mathrm{CCl} 4$ that were treated with saline or enoxaparin were pooled in a single control group (Pooled CTRLs). The graph shows Kaplan-Meier survival curves. The gray box represents the period of administration of saline or enoxaparin. The Log-rank Test was used to compare the survival curves of all groups $(P=.020)$. Post hoc multiple comparisons with Bonferroni's correction showed $P=.002$ for Pooled CTRLs vs CCl4 ${ }_{\text {ORAL }}+$ Enox 180 . Abbreviations: $\mathrm{CCl}_{\mathrm{ORAL}}$, carbon tetrachloride administered by oral gavage; Enox40, enoxaparin $40 \mathrm{IU} / \mathrm{Kg} /$ day s.c; Enox 180, enoxaparin $180 \mathrm{IU} / \mathrm{Kg} /$ day s.c; Sal, $0.9 \%$ saline s.c.

In the BDL experimental model, survival at week 5 was excellent in all groups with only one rat of the BDL+Enox180 group dying earlier (Pooled Shams: 100\% vs BDL+Sal: 100\% vs BDL+Enox180: 90\%, NS).

Blood tests were similarly altered in the $\mathrm{CCl} 4_{\mathrm{ORAL}}+\mathrm{Sal}$ and $\mathrm{CCl} 4_{\mathrm{ORAL}}+$ Enox 40 groups compared with controls (Table 1). Both groups of rats receiving CCl4 developed leukocytosis, thrombocytopenia, lower glycaemia, hypertransaminasemia and similar deterioration of parameters reflecting liver function (INR, total bilirubin and albumin). The decrease in fibrinogen level was significant only in the $\mathrm{CCl}_{\mathrm{ORAL}}+$ Enox 40 group. Arterial blood gases and kidney function parameters were normal in all groups, except for a slight increase in potassium in CCl4 rats (Supplementary Table 2).

Fortea, J. I.; Zipprich, A.; Fernandez-Mena, C.; Puerto, M.; Bosoi, C. R.; Almagro, J.; Hollenbach, M.; Bañares, J.; Rodríguez-Sánchez, B.; Cercenado, E.; Clément, M.-A.; Rose, C. F.; Bañares, R.; Vaquero, J. \& Ripoll, C. Enoxaparin does not ameliorate liver fibrosis or portal hypertension in rats with advanced cirrhosis. Liver international 2018, 38, 102-112 
This is the peer reviewed version of the following article: Fortea, J. I.; Zipprich, A.; Fernandez-Mena, C.; Puerto, M.; Bosoi, C. R.; Almagro, J.; Hollenbach, M.; Bañares, J.; Rodríguez-Sánchez, B.; Cercenado, E.; Clément, M.-A.; Rose, C. F.; Bañares, R.; Vaquero, J. \& Ripoll, C. Enoxaparin does not ameliorate liver fibrosis or portal hypertension in rats with advanced cirrhosis. Liver international 2018, $38,102-112$, which has been published in final form at 10.1111/liv.13510. This article may be used for non-commercial purposes in accordance with Wiley Terms and Conditions for Use of Self-Archived Versions.

Table 1. Haematological and blood biochemical parameters

\begin{tabular}{|c|c|c|c|c|c|c|}
\hline & \multicolumn{3}{|c|}{ Oral CCl4 model } & \multicolumn{3}{|c|}{ BDL model } \\
\hline & $\begin{array}{l}\text { Pooled } \\
\text { CTRLs }\end{array}$ & $\mathrm{CCl}_{\mathrm{ORAL}}+\mathrm{Sal}$ & $\mathrm{CCl}_{\mathrm{ORAL}}+$ Enox40 & $\begin{array}{l}\text { Pooled } \\
\text { SHAMs }\end{array}$ & BDL+Sal & BDL+Enox180 \\
\hline $\begin{array}{l}\text { Haemoglobin } \\
\text { (gr/dL) }\end{array}$ & $\begin{array}{l}14.1[13.8, \\
14.4]\end{array}$ & $\begin{array}{l}13.2[12.5, \\
13.6]\end{array}$ & $13.0[11.8,14.5]$ & & & \\
\hline $\begin{array}{l}\text { White blood cells } \\
(10 \times 3 / \mu \mathrm{L})\end{array}$ & $\begin{array}{l}1.3[0.9, \\
1.5]\end{array}$ & $\begin{array}{l}7.2[2.6 \\
15.8]^{* *}\end{array}$ & $6.6[5.3,15.1]^{* *}$ & & & \\
\hline $\begin{array}{l}\text { Platelets } \\
(10 \times 3 / \mu \mathrm{L})\end{array}$ & $\begin{array}{l}874[838, \\
934]\end{array}$ & $\begin{array}{l}525[363, \\
706]^{*}\end{array}$ & $357[153,637] * *$ & & & \\
\hline Glucose (mg/dL) & $\begin{array}{l}197[166, \\
234]\end{array}$ & $\begin{array}{l}122[104, \\
162]^{* *}\end{array}$ & $120[102,141]^{* *}$ & & & \\
\hline $\operatorname{ALT}(\mathbf{U} / \mathbf{L})$ & $28[25,37]$ & $68[54,89]^{* *}$ & $97[77,107]^{* * *}$ & $33[23,40]$ & $28[17,38]$ & $45[31,56]$ \\
\hline INR & $\begin{array}{l}1.2[1.1, \\
1.2]\end{array}$ & $1.5[1.2,1.6]^{* *}$ & $1.4[1.3,1.6]^{* *}$ & $\begin{array}{l}0.9[0.9, \\
1.0]\end{array}$ & $\begin{array}{l}1.6[1.1, \\
1.9]^{* *}\end{array}$ & $1.8[0.9,1.8]$ \\
\hline Fibrinogen (mg/dL) & $\begin{array}{l}211[194, \\
225]\end{array}$ & $128[87,199]$ & $100[69,111]^{* *}$ & & & \\
\hline $\begin{array}{l}\text { Total bilirubin } \\
\text { (mg/dL) }\end{array}$ & $\begin{array}{l}0.1[0.1, \\
0.1]\end{array}$ & $0.5[0.3,1.0]^{*}$ & $1.2[0.7,1.3]^{* * *}$ & $\begin{array}{l}0.4[0.2, \\
0.7]\end{array}$ & $\begin{array}{l}4.8[3.2, \\
5.8]^{* *}\end{array}$ & $3.2[1.2,4.8]^{*}$ \\
\hline Albumin (g/dL) & $\begin{array}{l}3.5[3.5, \\
3.7]\end{array}$ & $2.5[1.9,2.7]^{* *}$ & $2.2[2.1,2.4]^{* * *}$ & & & \\
\hline
\end{tabular}

$* P<.05$ vs Pooled CTRLs or Pooled SHAMs, $* * P<.01$ vs Pooled CTRLs or Pooled SHAMs, $* * * P<.001$ vs. Pooled CTRLs.

The BDL+Sal and BDL+Enox180 groups developed increases in total bilirubin in blood compared with Sham-operated rats, but only the BDL+Sal group showed a significant increase in INR $(P=.0096)$ (Table 1). All BDL groups showed normal ALT levels.

\section{LIVER FIBROSIS}

Administration of $\mathrm{CCl}_{\text {ORAL }}$ led to consistent development of fibrosis and macro-micro nodular cirrhosis regardless of enoxaparin treatment (Figure 3A-D). Compared with the Pooled CTRLs group $[0.7 \%(0.6,1.2)]$, the area of liver fibrosis was similarly increased in the CCl4 ${ }_{\mathrm{ORAL}}+\mathrm{Sal}[15.9 \%(12.0$, 17.8), $P<.01]$ and $\mathrm{CCl} 4_{\mathrm{ORAL}}+$ Enox40 [17.4\% (16.2, 20.6), $\left.P<.001\right]$ groups, as assessed by the Sirius Red staining (Figure 3A). Similar results were obtained with the Masson's Trichrome staining [Pooled CTRLs: $0.22 \%(0.12,0.34)$, vs CCl4 ${ }_{\mathrm{ORAL}}+\mathrm{Sal}: 3.99 \%(2.70,4.63)$ and $\mathrm{CCl}_{\mathrm{ORAL}}+\mathrm{Enox}_{40: 5.08 \%}$ (4.30, 8.06), $P<.01$ and $P<.001$ respectively].

Fortea, J. I.; Zipprich, A.; Fernandez-Mena, C.; Puerto, M.; Bosoi, C. R.; Almagro, J.; Hollenbach, M.; Bañares, J.; Rodríguez-Sánchez, B.; Cercenado, E.; Clément, M.-A.; Rose, C. F.; Bañares, R.; Vaquero, J. \& Ripoll, C. Enoxaparin does not ameliorate liver fibrosis or portal hypertension in rats with advanced cirrhosis. Liver international 2018, 38, 102-112 
This is the peer reviewed version of the following article: Fortea, J. I.; Zipprich, A.; Fernandez-Mena, C.; Puerto, M.; Bosoi, C. R.; Almagro, J.; Hollenbach, M.; Bañares, J.; Rodríguez-Sánchez, B.; Cercenado, E.; Clément, M.-A.; Rose, C. F.; Bañares, R.; Vaquero, J. \& Ripoll, C. Enoxaparin does not ameliorate liver fibrosis or portal hypertension in rats with advanced cirrhosis. Liver international 2018, $38,102-112$, which has been published in final form at 10.1111/liv.13510. This article may be used for non-commercial purposes in accordance with Wiley Terms and Conditions for Use of Self-Archived Versions.
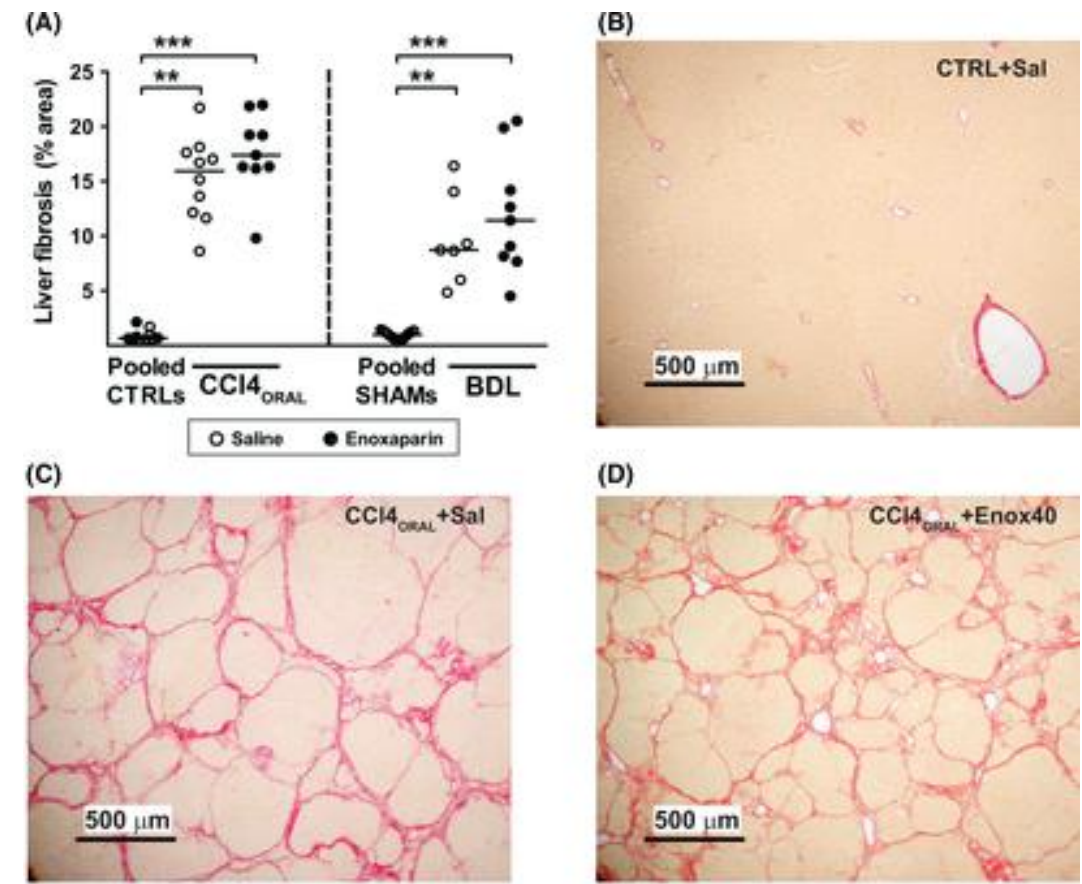

(D)

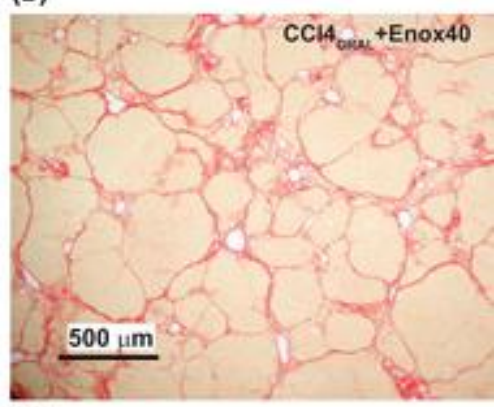

(E)

(F)
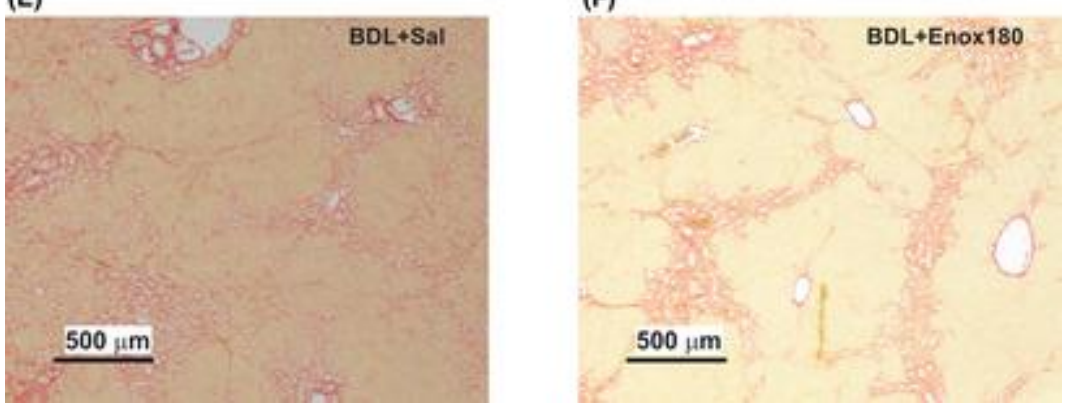

Figure 3 Effect of enoxaparin on liver fibrosis in rats with cirrhosis induced by oral gavage with $\mathrm{CCl} 4\left(\mathrm{CCl} 4_{\mathrm{ORAL}}\right)$ or by bile duct ligation (BDL). (A) Quantification of the area of fibrosis (\%) in Sirius Red stained liver sections. The line and dots represent the median and individual rat values respectively. $* * P<.01$, $* * * P<.001$ (Kruskal-Wallis with Dunn's post hoc tests). (B-F) Representative pictures of Sirius Red stained liver sections from a control rat receiving oral gavage with water (B), a rat with cirrhosis induced by oral gavage with CCl4 treated with saline (C) or with enoxaparin $40 \mathrm{IU} / \mathrm{Kg} / \mathrm{day}$ s.c. from week 8 of CCl4 (D) and a rat with cirrhosis induced by BDL treated with saline (E) or enoxaparin $180 \mathrm{IU} / \mathrm{Kg} / \mathrm{day}$ from week 1 after the surgery $(\mathrm{F})$

Rats undergoing BDL developed biliary cirrhosis with extensive bile-duct proliferation and periductal fibrosis regardless of enoxaparin treatment (Figure 3E-F). Compared with the Pooled SHAMs group $[1.0 \%(0.7,1.3)]$, the area of fibrosis was similarly increased in the BDL+Sal $[8.7 \%(6.0,14.1)$, $P<.01]$ and the BDL+Enox180 [11.4\% (7.9, 17.1), $P<.001]$ groups, as assessed by Sirius Red staining (Figure 3A).

Fortea, J. I.; Zipprich, A.; Fernandez-Mena, C.; Puerto, M.; Bosoi, C. R.; Almagro, J.; Hollenbach, M.; Bañares, J.; Rodríguez-Sánchez, B.; Cercenado, E.; Clément, M.-A.; Rose, C. F.; Bañares, R.; Vaquero, J. \& Ripoll, C. Enoxaparin does not ameliorate liver fibrosis or portal hypertension in rats with advanced cirrhosis. Liver international 2018, 38, 102-112 
This is the peer reviewed version of the following article: Fortea, J. I.; Zipprich, A.; Fernandez-Mena, C.; Puerto, M.; Bosoi, C. R.; Almagro, J.; Hollenbach, M.; Bañares, J.; Rodríguez-Sánchez, B.; Cercenado, E.; Clément, M.-A.; Rose, C. F.; Bañares, R.; Vaquero, J. \& Ripoll, C. Enoxaparin does not ameliorate liver fibrosis or portal hypertension in rats with advanced cirrhosis. Liver international 2018, $38,102-112$, which has been published in final form at 10.1111/liv.13510. This article may be used for non-commercial purposes in accordance with Wiley Terms and Conditions for Use of Self-Archived Versions.

The expression of Colla1, Acta2 and Timp1 mRNAs was markedly induced in the liver of cirrhotic rats, but enoxaparin had no influence neither in the CCl4 ${ }_{\text {ORAL }}$ nor the BDL models (Figure 4A-C). Likewise, the protein expression of platelet-derived growth factor receptor- $\beta$ and $\alpha$-smooth muscle actin was similarly increased in the liver of CCL4 $4_{\text {ORAL }}$ rats regardless of enoxaparin treatment (Figure 4D).
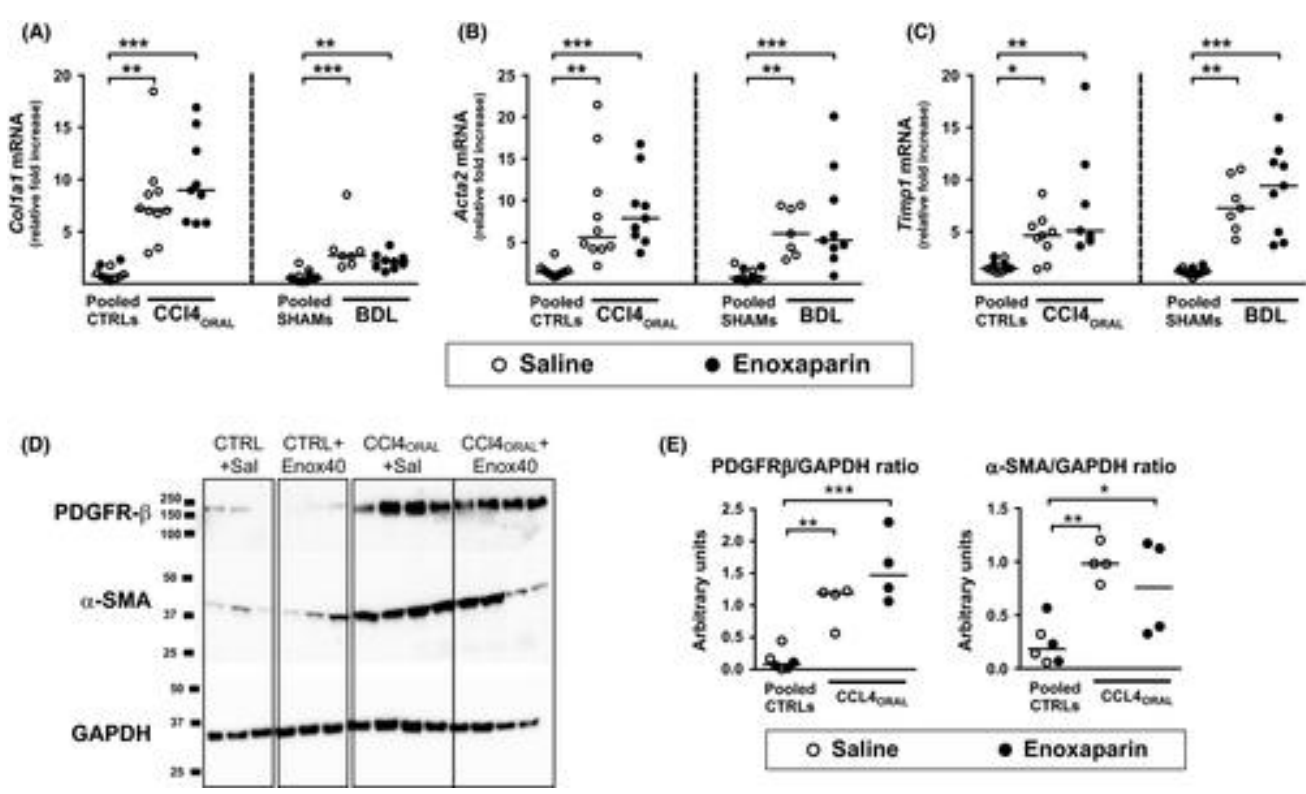

Figure 4 Effect of enoxaparin on the expression of fibrosis-related genes and proteins. The graphs show the mRNA expression of (A) collagen 1-alpha (Collal), (B) alpha-smooth muscle actin (Acta2) and (C) TIMP metallopeptidase inhibitor 1 (Timp1) in liver tissue from rats with cirrhosis induced by oral gavage with $\mathrm{CCl} 4\left(\mathrm{CCl} 4_{\mathrm{ORAL}}\right)$ or by bile duct ligation (BDL). (D) Representative Western blots of platelet-derived growth factor receptor- $\beta$ (PDGFR-b), $\alpha$-smooth muscle actin (a-SMA), and glyceraldehyde-3-phosphate dehydrogenase (GAPDH) in livers from CCl4 ${ }_{\mathrm{ORAL}}$ rats and their controls, with (E) their corresponding densitometric analyses. In each experimental model, rats treated with saline or enoxaparin that received oral gavage with water (Pooled CTRLs) or sham surgery (Pooled SHAMs) were pooled. Enoxaparin dose was $40 \mathrm{IU} / \mathrm{Kg} /$ day in the $\mathrm{CCl} 4_{\mathrm{ORAL}}$ model and $180 \mathrm{IU} / \mathrm{Kg} /$ day in the BDL model. The line and dots represent the median and individual rat values, respectively. ${ }^{*} P<.05, * * P<.01, * * * P<.001$ (Kruskal-Wallis with Dunn's post hoc tests)

\section{DEVELOPMENT OF PORTAL HYPERTENSION}

Enoxaparin did not prevent the development of ascites in rats receiving CCl4 $\left(\mathrm{CCl} 4_{\mathrm{ORAL}}+\mathrm{Sal}: 80 \%\right.$ vs $\mathrm{CCl}_{\mathrm{ORAL}}+\mathrm{Enox} 40: 100 \%, P=.47$ ) or in BDL rats (BDL+Sal: 86\% vs BDL+Enox180: 70\%, $\left.P=.60\right)$. None of the control rats had ascites.

Enoxaparin administration had no relevant effects on heart rate, mean arterial pressure or respiratory rate in any of the experimental models, although heart rates were decreased in BDL groups compared with the SHAM+Enox180 group (Supplementary Table 3). Rats with CCl4-induced cirrhosis showed marked increases in portal pressure [Pooled CTRLs: $6.07 \mathrm{mmHg}(5.11,7.35), \mathrm{CCl}_{\mathrm{ORAL}}+\mathrm{Sal}$ :

Fortea, J. I.; Zipprich, A.; Fernandez-Mena, C.; Puerto, M.; Bosoi, C. R.; Almagro, J.; Hollenbach, M.; Bañares, J.; Rodríguez-Sánchez, B.; Cercenado, E.; Clément, M.-A.; Rose, C. F.; Bañares, R.; Vaquero, J. \& Ripoll, C. Enoxaparin does not ameliorate liver fibrosis or portal hypertension in rats with advanced cirrhosis. Liver international 2018, 38, 102-112 
This is the peer reviewed version of the following article: Fortea, J. I.; Zipprich, A.; Fernandez-Mena, C.; Puerto, M.; Bosoi, C. R.; Almagro, J.; Hollenbach, M.; Bañares, J.; Rodríguez-Sánchez, B.; Cercenado, E.; Clément, M.-A.; Rose, C. F.; Bañares, R.; Vaquero, J. \& Ripoll, C. Enoxaparin does not ameliorate liver fibrosis or portal hypertension in rats with advanced cirrhosis. Liver international 2018, $38,102-112$, which has been published in final form at 10.1111/liv.13510. This article may be used for non-commercial purposes in accordance with Wiley Terms and Conditions for Use of Self-Archived Versions.

$14.47 \mathrm{mmHg}(14.03,16.16), \mathrm{CCl}_{\mathrm{ORAL}}+$ Enox40: $12.43 \mathrm{mmHg}(11.11,15.03)$, ANOVA $\left.P<.0001\right]$ and of the spleen-to-BW ratio [Pooled CTRLs: $0.165 \%$ (0.158, 0.190), CCl4 ${ }_{\text {ORAL }}+$ Sal: $0.430 \%$ (0.345, 0.485), CCl4 ${ }_{\text {ORAL }}+$ Enox 40: 0.470\% $(0.375,0.505)$, Kruskal-Wallis test $\left.P<.0001\right]$, none of which was influenced by enoxaparin treatment (Figure 5A,B). Similarly, BDL rats also developed increases in portal pressure [Pooled Shams: $6.15 \mathrm{mmHg}$ (5.03, 7.38), BDL+Sal: $11.50 \mathrm{mmHg}(9.50,14.50)$, BDL+Enox180: $15.68 \mathrm{mmHg}(13.62,16.73)$, ANOVA $P<.0001]$ and of the spleen-to-BW ratio [Pooled Shams: 0.195\% (0.168, 0.200), BDL+Sal: 0.735\% (0.700, 0.793), BDL+Enox180: 0.660\% $(0.570,0.930)$, Kruskal-Wallis test $P<0$.01) with respect to the Pooled Shams group (Figure 5A,B). Of note, enoxaparin worsened portal hypertension in BDL rats $(P<.05 \mathrm{BDL}+\mathrm{Sal}$ vs BDL + Enox180).

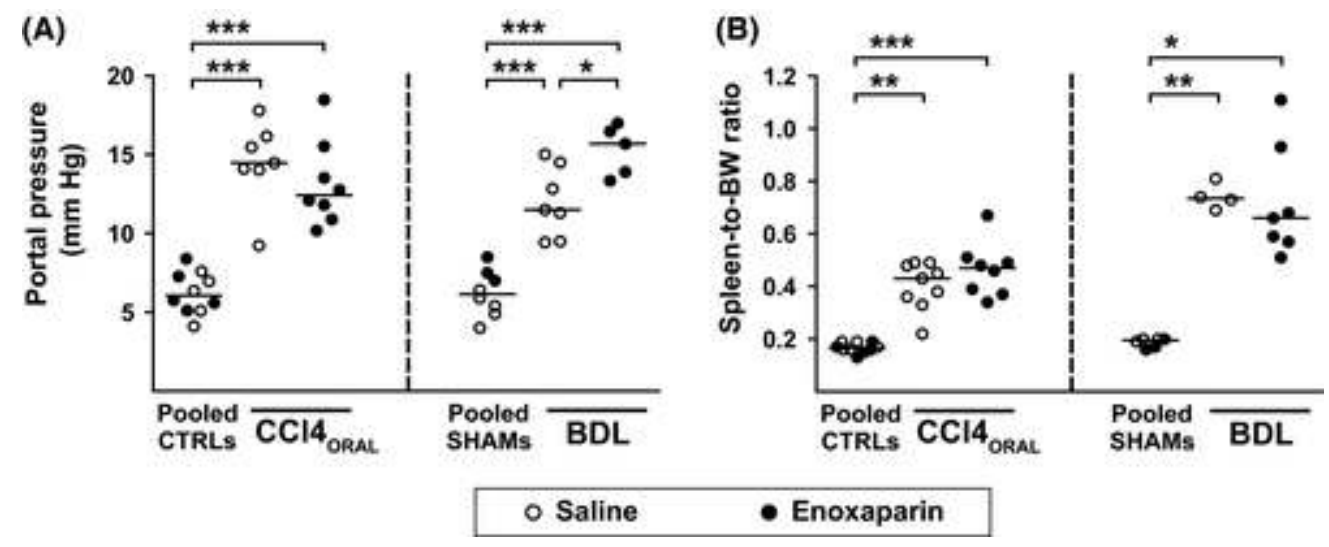

Figure 5 Effect of enoxaparin on the development of portal hypertension in rats with cirrhosis induced by oral gavage with $\mathrm{CCl} 4\left(\mathrm{CCl} 4_{\mathrm{ORAL}}\right)$ or by bile duct ligation (BDL). The graphs show (A) portal pressure values and (B) spleen-to-body weight ratios in individual rats. In each experimental model, control rats treated with saline or enoxaparin that received oral gavage with water (Pooled CTRLs) or sham surgery (Pooled SHAMs) were pooled. Enoxaparin dose was $40 \mathrm{IU} / \mathrm{Kg} / \mathrm{day}$ in the $\mathrm{CCl} 4_{\mathrm{ORAL}}$ model and $180 \mathrm{IU} / \mathrm{Kg} /$ day in the $\mathrm{BDL}$ model. The line and dots represent the median and individual rat values. $* P<.05,{ }^{* *} P<.01,{ }^{* * *} P<.001$ (Kruskal-Wallis with Dunn's post hoc tests)

To assess for subtler effects of enoxaparin on the hepatic vascular endothelium, we evaluated the expression of endothelial nitric-oxide synthase (eNOS) and vascular endothelial growth factor (VEGF) in liver tissue (Figure 6A-D). The mRNA and protein expression of eNOS were not affected by the development of cirrhosis or by enoxaparin treatment in the CC14 model, although some rats receiving enoxaparin showed marked up-regulation of Enos mRNA. No significant changes in Enos mRNA expression were observed in BDL rats. Compared with controls, the Vegfa mRNA expression was decreased in cirrhotic rats regardless of enoxaparin administration both in the CC14 $\mathrm{ORAL}$ and the BDL models (Figure 6B). In contrast, the protein expression of VEGF was increased in the livers of $\mathrm{CCl} 4_{\mathrm{ORAL}}$ rats $(P<.05)$ regardless of enoxaparin treatment (Figure 6C,D).

Fortea, J. I.; Zipprich, A.; Fernandez-Mena, C.; Puerto, M.; Bosoi, C. R.; Almagro, J.; Hollenbach, M.; Bañares, J.; Rodríguez-Sánchez, B.; Cercenado, E.; Clément, M.-A.; Rose, C. F.; Bañares, R.; Vaquero, J. \& Ripoll, C. Enoxaparin does not ameliorate liver fibrosis or portal hypertension in rats with advanced cirrhosis. Liver international 2018, 38, 102-112 
This is the peer reviewed version of the following article: Fortea, J. I.; Zipprich, A.; Fernandez-Mena, C.; Puerto, M.; Bosoi, C. R.; Almagro, J.; Hollenbach, M.; Bañares, J.; Rodríguez-Sánchez, B.; Cercenado, E.; Clément, M.-A.; Rose, C. F.; Bañares, R.; Vaquero, J. \& Ripoll, C. Enoxaparin does not ameliorate liver fibrosis or portal hypertension in rats with advanced cirrhosis. Liver international 2018, $38,102-112$, which has been published in final form at 10.1111/liv.13510. This article may be used for non-commercial purposes in accordance with Wiley Terms and Conditions for Use of Self-Archived Versions.
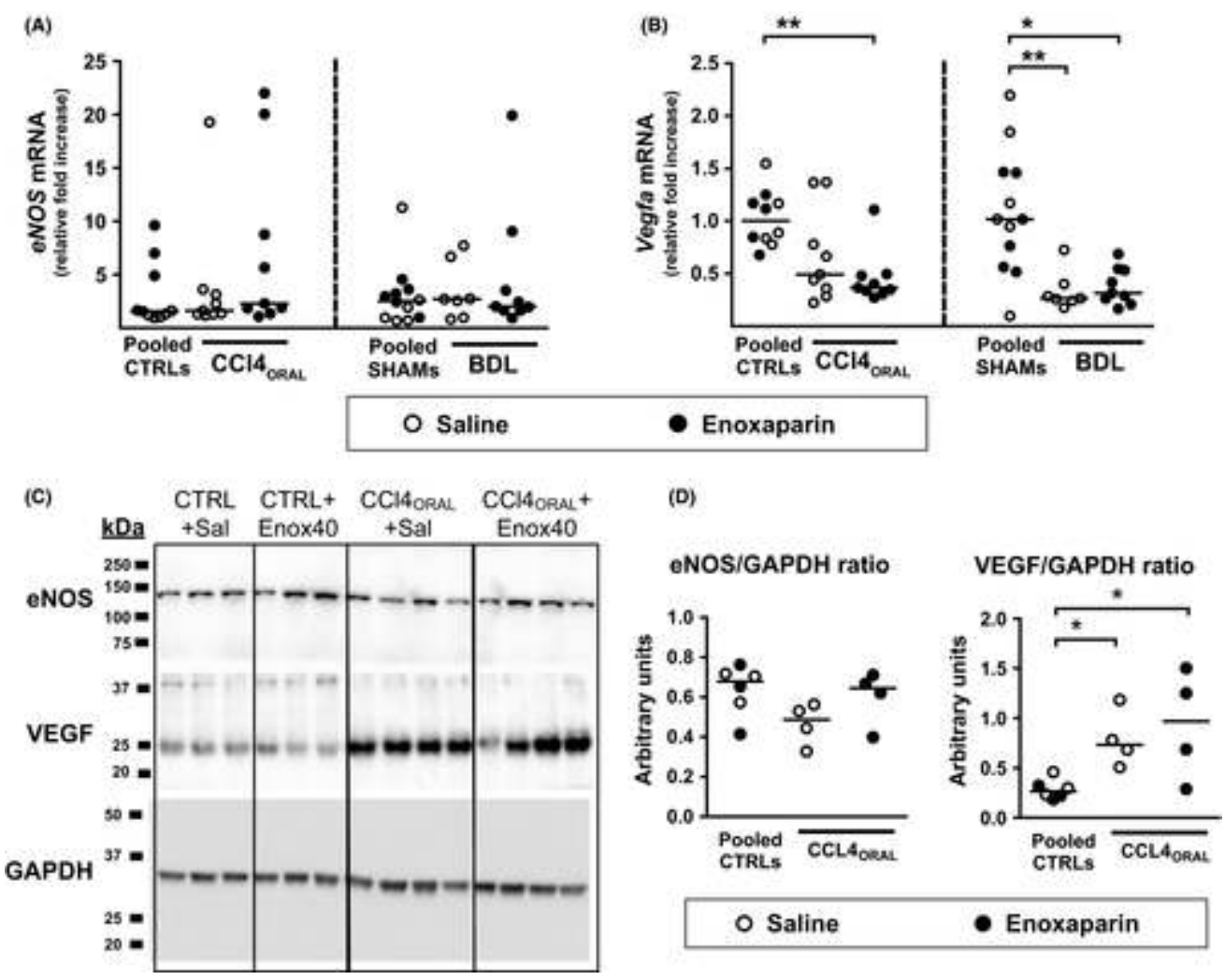

Figure 6 Effect of enoxaparin on the expression of endothelium-related genes and proteins. The graphs show the mRNA expression of (A) endothelial nitric-oxide synthase (eNOS), and (B) vascular endothelial growth factor A (Vegfa) in liver tissue from rats with cirrhosis induced by oral gavage with $\mathrm{CCl} 4\left(\mathrm{CCl} 4_{\mathrm{ORAL}}\right)$ or by bile duct ligation (BDL). (C) Representative Western blots of eNOS and vascular endothelial growth factor (VEGF) in livers from $\mathrm{CCl}_{\mathrm{ORAL}}$ rats and their controls, with (D) their corresponding densitometric analyses. In each experimental model, rats treated with saline or enoxaparin that received oral gavage with water (Pooled CTRLs) or sham surgery (Pooled SHAMs) were pooled.

Enoxaparin dose was $40 \mathrm{IU} / \mathrm{Kg} /$ day in the $\mathrm{CCl} 4_{\mathrm{ORAL}}$ model and $180 \mathrm{IU} / \mathrm{Kg} /$ day in the BDL model. The line and dots represent the median and individual rat values respectively. ${ }^{*} P<.05$, $* * P<.01$, $* * * P<.001$ (Kruskal-Wallis with Dunn's post hoc tests)

Among rats with ascites, the proportion that presented positive bacterial cultures of ascites were similar in the $\mathrm{CCl}_{\mathrm{ORAL}}+\mathrm{Sal}$ and $\mathrm{CCl} 4_{\mathrm{ORAL}}+$ Enox40 groups [2 of $7(28.6 \%)$ vs 4 of $\left.8(50 \%), P=.61\right]$. Both groups also had similar levels of circulating IL-6 (349 $\pm 138 \mathrm{pg} / \mathrm{mL}$ vs $248 \pm \mathrm{pg} / \mathrm{mL}, P=.89)$.

Among BDL rats with ascites, the proportion of rats with positive bacterial cultures was also similar in the BDL+Sal and BDL+Enox180 groups [1 of $6(16.7 \%)$ vs 2 of $7(28.6 \%), P=1.0]$. The circulating levels of IL-6 were also similar in both groups $(278 \pm 103 \mathrm{pg} / \mathrm{mL}$ vs $370 \pm 168 \mathrm{pg} / \mathrm{mL}, P=.94)$.

\section{CIRRHOSIS -ASSOCIATED MICROCIRCULATORY DYSFUNCTION OF HEPATIC VASCULAR BED}

Fortea, J. I.; Zipprich, A.; Fernandez-Mena, C.; Puerto, M.; Bosoi, C. R.; Almagro, J.; Hollenbach, M.; Bañares, J.; Rodríguez-Sánchez, B.; Cercenado, E.; Clément, M.-A.; Rose, C. F.; Bañares, R.; Vaquero, J. \& Ripoll, C. Enoxaparin does not ameliorate liver fibrosis or portal hypertension in rats with advanced cirrhosis. Liver international 2018, 38, 102-112 
This is the peer reviewed version of the following article: Fortea, J. I.; Zipprich, A.; Fernandez-Mena, C.; Puerto, M.; Bosoi, C. R.; Almagro, J.; Hollenbach, M.; Bañares, J.; Rodríguez-Sánchez, B.; Cercenado, E.; Clément, M.-A.; Rose, C. F.; Bañares, R.; Vaquero, J. \& Ripoll, C. Enoxaparin does not ameliorate liver fibrosis or portal hypertension in rats with advanced cirrhosis. Liver international 2018, $38,102-112$, which has been published in final form at 10.1111/liv.13510. This article may be used for non-commercial purposes in accordance with Wiley Terms and Conditions for Use of Self-Archived Versions.

To assess the effects of enoxaparin on the hepatic microcirculation, we performed in situ liver perfusion experiments in rats with cirrhosis induced by $\mathrm{CCl}_{\mathrm{INH}}$ (Figure 1, experiments C.1 and C.2). In these experiments, survival of rats treated with saline or enoxaparin was, respectively, $91.2 \%$ (31 of $34)$ and $94.4 \%$ (34 of 36) in those with 8 weeks of CCl4 inhalation $(P=.67)$, and $74.1 \%$ (20 of 27) and $57.6 \%$ (19 of 33) in those with 12 weeks of CCl4 inhalation $(P=.28)$.

In rats with 8 weeks of $\mathrm{CCl} 4$ inhalation (experiment C.1), the absolute values of portal venous resistance were higher in enoxaparin-treated than in saline-treated rats at baseline and at all concentrations of acetylcholine $(P=.048)$ and S-Nitroso-N-acetyl-DL-penicillamine (SNAP, $P=.005)$ tested (Figure 7A,B). The percent changes in portal venous resistance from methoxamine-induced preconstriction, however, were virtually identical in saline- and enoxaparin-treated rats in response to acetylcholine $(P=.35)$ and to SNAP $(P=.45)$ (Supplementary Figure 1A,B). Similarly, the absolute values of sinusoidal resistance were higher in enoxaparin-treated rats at all concentrations of SNAP tested $(P=.027)$, but not of acetylcholine $(P=.26)$ (Figure 7C,D). The percent reduction in sinusoidal resistance from methoxamine-induced preconstriction was similar in both groups in response to acetylcholine $(P=.076)$ and to SNAP $(P=.41)$ (Supplementary Figure $1 \mathrm{C}, \mathrm{D})$. Noteworthy, the area of liver fibrosis (Sirius Red staining) was increased in enoxaparin-treated rats $\left[\mathrm{CCl}_{\mathrm{INH}}+\mathrm{Sal}\right.$ : $10.7 \%$ (7.6, 13.6) vs $\mathrm{CCl}_{\mathrm{INH}}+$ Enox 180: $\left.20.7 \%(11.0,22.2), P=.029\right]$ (Supplementary Figure 2).

Fortea, J. I.; Zipprich, A.; Fernandez-Mena, C.; Puerto, M.; Bosoi, C. R.; Almagro, J.; Hollenbach, M.; Bañares, J.; Rodríguez-Sánchez, B.; Cercenado, E.; Clément, M.-A.; Rose, C. F.; Bañares, R.; Vaquero, J. \& Ripoll, C. Enoxaparin does not ameliorate liver fibrosis or portal hypertension in rats with advanced cirrhosis. Liver international 2018, 38, 102-112 
This is the peer reviewed version of the following article: Fortea, J. I.; Zipprich, A.; Fernandez-Mena, C.; Puerto, M.; Bosoi, C. R.; Almagro, J.; Hollenbach, M.; Bañares, J.; Rodríguez-Sánchez, B.; Cercenado, E.; Clément, M.-A.; Rose, C. F.; Bañares, R.; Vaquero, J. \& Ripoll, C. Enoxaparin does not ameliorate liver fibrosis or portal hypertension in rats with advanced cirrhosis. Liver international 2018, $38,102-112$, which has been published in final form at 10.1111/liv.13510. This article may be used for non-commercial purposes in accordance with Wiley Terms and Conditions for Use of Self-Archived Versions.
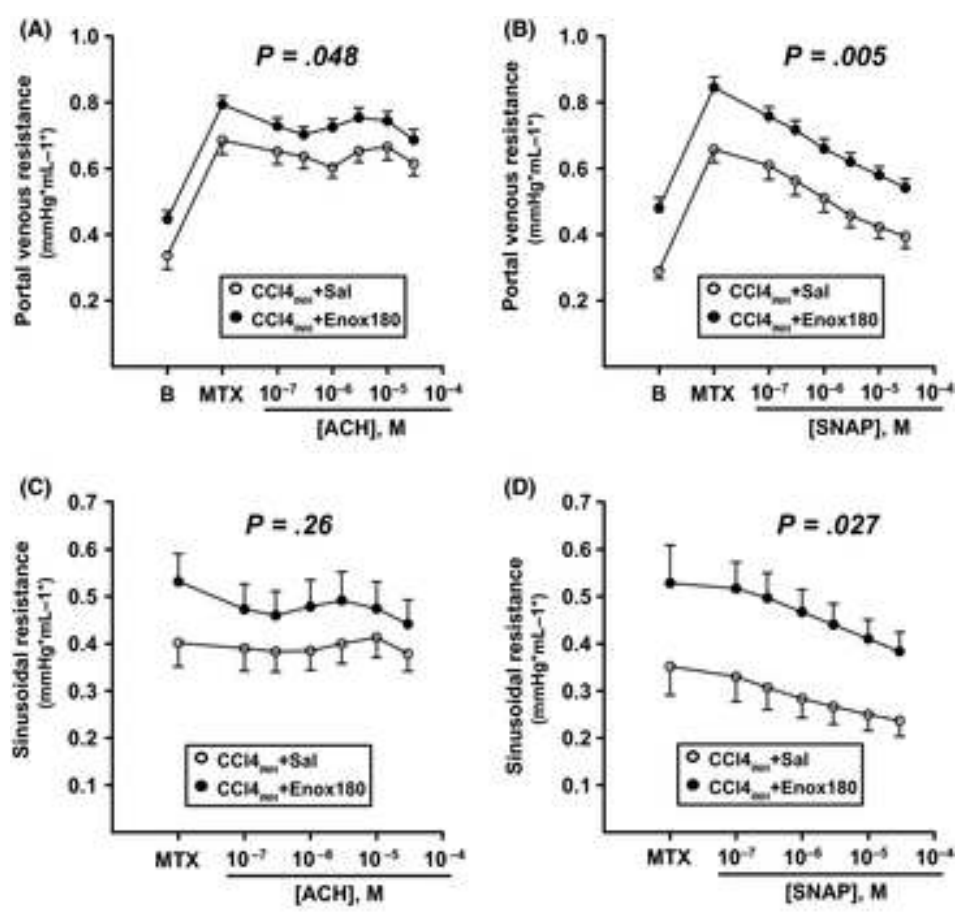

(E)

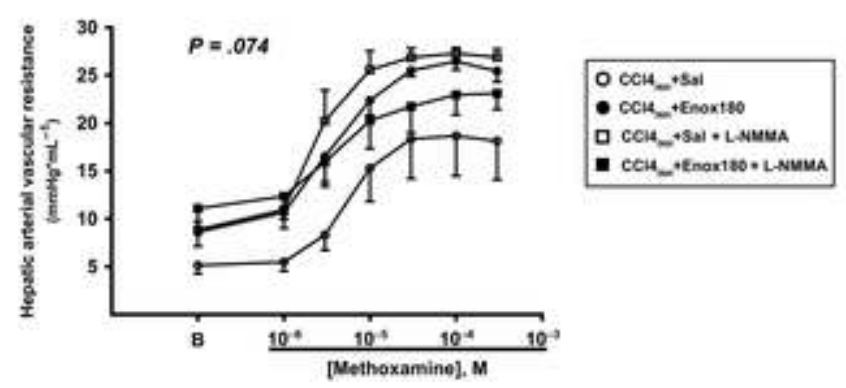

Figure 7 Effect of enoxaparin on the portal vascular bed reactivity (A-D) and on the hepatic arterial vascular resistance (E) assessed by in situ liver perfusions in rats with cirrhosis induced by 8 weeks of $\mathrm{CCl} 4$ inhalation $\left(\mathrm{CCl} 4_{\mathrm{INH}}\right)$. Absolute values of $(\mathrm{A}, \mathrm{B})$ portal venous resistance and $(\mathrm{C}, \mathrm{D})$ sinusoidal resistance in response to increasing concentrations of acetylcholine $(\mathrm{ACH})$ and S-Nitroso-N-acetyl-DL-penicillamine (SNAP). Groups were compared by a General Linear Model for Repeated Measurements. (E) Absolute values of hepatic arterial vascular resistance in response to increasing concentrations of methoxamine in the presence or absence of L-NMMA. Groups were compared by a General Linear Model for Repeated Measurements $(P=.074)$, followed by LSD post hoc tests $(\mathrm{CCl} 4-\mathrm{Sal}$ vs CCl4-Sal+LNMMA $P=.036, \mathrm{CCl} 4-\mathrm{Enox} 180$ vs CCl4-Enox180+LNMMA $P=.67$, CCl4-Sal vs CCl4-Enox $180 P=.025$, CCl4-Sal+LNMMA vs CCl4-Enox180+LNMMA $P=.45)$. Rats were treated with saline (Sal) or enoxaparin (180 IU/Kg/day, Enox 180) for the full period of CCl4 administration. Abbreviations: B, baseline; MTX, preconstriction with methoxamine

Regarding the hepatic artery, cirrhotic rats treated with saline showed lower hepatic arterial vascular resistances and an upward shift of the curve in response to methoxamine when $\mathrm{N}^{\mathrm{G}}$-Methyl-L-arginine acetate salt (L-NMMA), an inhibitor of nitric oxide synthesis, was added to the perfusion fluid, reflecting the characteristic dysfunction (nitric-oxide overproduction) of the hepatic artery in cirrhosis

Fortea, J. I.; Zipprich, A.; Fernandez-Mena, C.; Puerto, M.; Bosoi, C. R.; Almagro, J.; Hollenbach, M.; Bañares, J.; Rodríguez-Sánchez, B.; Cercenado, E.; Clément, M.-A.; Rose, C. F.; Bañares, R.; Vaquero, J. \& Ripoll, C. Enoxaparin does not ameliorate liver fibrosis or portal hypertension in rats with advanced cirrhosis. Liver international 2018, 38, 102-112 
This is the peer reviewed version of the following article: Fortea, J. I.; Zipprich, A.; Fernandez-Mena, C.; Puerto, M.; Bosoi, C. R.; Almagro, J.; Hollenbach, M.; Bañares, J.; Rodríguez-Sánchez, B.; Cercenado, E.; Clément, M.-A.; Rose, C. F.; Bañares, R.; Vaquero, J. \& Ripoll, C. Enoxaparin does not ameliorate liver fibrosis or portal hypertension in rats with advanced cirrhosis. Liver international 2018, $38,102-112$, which has been published in final form at 10.1111/liv.13510. This article may be used for non-commercial purposes in accordance with Wiley Terms and Conditions for Use of Self-Archived Versions.

$\left(\mathrm{CCl}_{\mathrm{INH}}+\right.$ Sal vs CCl4 $\left.\mathrm{IHN}+\mathrm{Sal}+\mathrm{L}-\mathrm{NMMA}, P=.036\right)$. Such feature, however, was not observed in cirrhotic rats treated with enoxaparin $\left(\mathrm{CCl}_{\mathrm{INH}}+\right.$ Enox180 vs. $\mathrm{CCl} 4_{\mathrm{IHN}}+$ Enox $\left.180+\mathrm{L}-\mathrm{NMMA}, P=.67\right)$ (Figure 7E).

In rats with more prolonged $\mathrm{CCl} 4$ exposure and low-dose enoxaparin (experiment C.2), the absolute values and the percent changes in the portal venous and sinusoidal resistance curves in response to acetylcholine and SNAP, as well as the hepatic arterial dysfunction characteristic of cirrhosis, were similar in saline- and enoxaparin-treated rats (Supplementary Figures 3 and 4).

\section{DISCUSSION}

Based on promising clinical and experimental observations, anticoagulants are attracting attention as a potential routine medication for patients with liver disease. In this study, however, several protocols of enoxaparin administration in a variety of experimental models of advanced cirrhosis in rats consistently failed to show the expected protective effects against liver fibrosis, portal hypertension and hepatic endothelial dysfunction. Biochemical parameters of liver function were not improved either. Although we noted some beneficial effects of enoxaparin, they were mostly marginal. Unsettlingly, we also observed pernicious effects of enoxaparin scattered across the diverse models, including decreased survival in $\mathrm{CCl}_{\mathrm{ORAL}}+$ Enox180 rats, increased portal venous resistance and liver fibrosis in $\mathrm{CCl}_{\mathrm{INH}}+$ Enox180 rats, or worsening portal hypertension in BDL+Enox180 rats. Remarkably, the different experimental models $\left(\mathrm{CCl}_{\mathrm{ORAL}}, \mathrm{BDL}, \mathrm{CCl}_{\mathrm{INH}}\right)$ were performed in three independent laboratories with expertise in each of them, but all coincided in the lack of conclusive benefits from enoxaparin. Collectively, our results suggest that the potential benefits of enoxaparin administration are largely diminished or lost at late stages of advanced cirrhosis. Those stages, however, are where therapies to influence the natural history of the disease are most needed.

The inability of enoxaparin to ameliorate liver fibrosis or the hepatic expression of profibrogenic genes reflecting hepatic stellate cell activation was a consistent observation in our study. These results differ from previous experimental studies reporting a protective effect of anticoagulants against liver fibrosis.10-13 Importantly, most of our protocols involved the initiation of enoxaparin once that cirrhosis was fully established and its continuation throughout late stages of advanced cirrhosis, whereas most prior studies started anticoagulation before the initiation of the hepatic insult or limited the evaluation to early stages of disease.10-13 Noteworthy, the reduction in liver fibrosis was generally modest in all prior studies, intragroup variability was higher than ours, and some low molecular weight heparins had no effect or even deleterious effects.10 Relevant methodological differences also exist with the study by Cerini et al., in which the effect on the extent of fibrosis was also modest:14 (a) their study involved a shorter administration of enoxaparin (3 weeks vs up to 7 weeks) that started in most cases 1 week after the discontinuation of $\mathrm{CCl} 4$ or thioacetamide, resembling a paradigm of cirrhosis regression rather than progression, (b) the intrahepatic vascular resistance was evaluated in vivo (vs in situ), (c) the rats were younger (50-75 vs 150-200 g bw) and (d) the extent of fibrosis and the degree of portal hypertension suggested less advanced disease. Therefore, major differences in experimental designs and methodology possibly explain the apparent contradictions with prior studies.

Fortea, J. I.; Zipprich, A.; Fernandez-Mena, C.; Puerto, M.; Bosoi, C. R.; Almagro, J.; Hollenbach, M.; Bañares, J.; Rodríguez-Sánchez, B.; Cercenado, E.; Clément, M.-A.; Rose, C. F.; Bañares, R.; Vaquero, J. \& Ripoll, C. Enoxaparin does not ameliorate liver fibrosis or portal hypertension in rats with advanced cirrhosis. Liver international 2018, 38, 102-112 
This is the peer reviewed version of the following article: Fortea, J. I.; Zipprich, A.; Fernandez-Mena, C.; Puerto, M.; Bosoi, C. R.; Almagro, J.; Hollenbach, M.; Bañares, J.; Rodríguez-Sánchez, B.; Cercenado, E.; Clément, M.-A.; Rose, C. F.; Bañares, R.; Vaquero, J. \& Ripoll, C. Enoxaparin does not ameliorate liver fibrosis or portal hypertension in rats with advanced cirrhosis. Liver international 2018, $38,102-112$, which has been published in final form at 10.1111/liv.13510. This article may be used for non-commercial purposes in accordance with Wiley Terms and Conditions for Use of Self-Archived Versions.

The vascular endothelium is a major site of action for heparin in the rat and other mammals, 19 although discordant effects of heparins have been reported regarding the modulation of vascular tone or endothelial-related genes.20-24 In our study, enoxaparin seemed to induce Enos expression in some individual rats, but overall eNOS mRNA and protein expression remained unchanged. Although cirrhosis was associated with changes in the expression of VEGF in liver tissue, such changes were not affected by enoxaparin either. In a recent study, rats receiving enoxaparin showed a reduction in portal hypertension related to a decrease in intrahepatic vascular resistance, which was explained by a reduction in liver fibrosis rather than by an improvement of endothelial cell function.14 Here, we performed a detailed examination using in vivo measurements of systemic and hepatic haemodynamics and in-situ liver perfusion experiments to specifically assess endothelial dysfunction in the portal venous and hepatic arterial vascular beds. As in the prior study, 14 enoxaparin did not influence systemic haemodynamic parameters such as mean arterial pressure or heart rate. However, we did not observe an attenuation of portal hypertension by enoxaparin in rats with CC14- or BDL-induced cirrhosis, as assessed by its direct measurement or by indirect markers such as the development of splenomegaly and ascites. On the contrary, enoxaparin was even associated with worsening of portal hypertension in BDL rats. Such observations were supported by the in situ liver perfusion experiments, in which the percent changes in portal venous resistance and sinusoidal resistance were almost identical in saline- and enoxaparin-treated rats. The increased absolute values of portal venous and sinusoidal resistance at all tested concentrations of vasodilators in enoxaparin-treated rats (experiment C.1) suggested worsening of an underlying static factor, likely related to the increased fibrosis of those livers. Although the high dose of enoxaparin corrected the endothelial dysfunction in the hepatic artery when it was administered in parallel with CCl4 (early cirrhosis, experiment C.1), such an effect was not observed when a prophylactic dose was started in rats with advanced cirrhosis (experiment C.2).

Consistent with the lack of effects on liver fibrosis and haemodynamics, enoxaparin influenced neither systemic inflammation nor bacterial translocation, two purported mechanisms of action. Prior studies showing increased anti-Xa activity in cirrhotic rats treated with $180 \mathrm{IU} / \mathrm{Kg} /$ day of enoxaparin 14 together with our results of anti-Xa activity make unlikely that the ineffectiveness of enoxaparin was caused by a lack of target engagement. It is conceivable that highly cross-linked collagen fibres and fibrotic acellular septa in advanced cirrhosis are not susceptible to potential antifibrotic effects of enoxaparin. Changes in intrahepatic inflammation or microthrombus formation could underlie deleterious effects of enoxaparin observed in our study. Heparin and low molecular weight heparins have been occasionally reported to increase platelet activation and aggregation, 25 and to promote a prothrombotic state shortly after its withdrawal in patients with unstable angina.26 In this regard, altered pharmacokinetics and/or pharmacodynamics of enoxaparin at advanced stages of liver disease should also be considered.

The increased mortality in $\mathrm{CCl} 4_{\mathrm{ORAL}}+\mathrm{Enox} 180$ rats appeared to obey to a more advanced liver disease, as no haemorrhagic complications were noted. Although mortality also tended to be higher in $\mathrm{CCl} 4_{\text {INH }}$ rats treated with enoxaparin compared with saline, the difference was not significant (42.4\% vs $25.9 \%$, $P=.28)$. To our knowledge, there are no potential interactions between enoxaparin and carbon tetrachloride or cytochrome P450 metabolism that could explain the increased mortality.

Fortea, J. I.; Zipprich, A.; Fernandez-Mena, C.; Puerto, M.; Bosoi, C. R.; Almagro, J.; Hollenbach, M.; Bañares, J.; Rodríguez-Sánchez, B.; Cercenado, E.; Clément, M.-A.; Rose, C. F.; Bañares, R.; Vaquero, J. \& Ripoll, C. Enoxaparin does not ameliorate liver fibrosis or portal hypertension in rats with advanced cirrhosis. Liver international 2018, 38, 102-112 
This is the peer reviewed version of the following article: Fortea, J. I.; Zipprich, A.; Fernandez-Mena, C.; Puerto, M.; Bosoi, C. R.; Almagro, J.; Hollenbach, M.; Bañares, J.; Rodríguez-Sánchez, B.; Cercenado, E.; Clément, M.-A.; Rose, C. F.; Bañares, R.; Vaquero, J. \& Ripoll, C. Enoxaparin does not ameliorate liver fibrosis or portal hypertension in rats with advanced cirrhosis. Liver international 2018, $38,102-112$, which has been published in final form at 10.1111/liv.13510. This article may be used for non-commercial purposes in accordance with Wiley Terms and Conditions for Use of Self-Archived Versions.

In conclusion, our results suggest that the beneficial effects of enoxaparin are lost or may even be detrimental at late stages of advanced liver disease or when the hepatic insult is ongoing. These factors and the possibility of a limited therapeutic window should be considered in clinical and experimental studies of anticoagulants in liver disease.

ACKNOWLEDGEMENTS

Work funded by ISCIII and Fondos FEDER to CR (PI11/00956). JV was supported by Ramón y Cajal grant (R\&C2010-05838) from MINECO, and CFM by IiSGM fellowship. The authors thank Dr. JM Bellón for statistical analyses, Julio García and Sabine Pohl for histological processing and Dr. A. Rodriguez-Huerta for anti-Xa activity analyses.

CONFLICT OF INTEREST

The authors do not have any disclosures to report.

\section{REFERENCES}

1. Tsochatzis EA, Bosch J, Burroughs AK. New therapeutic paradigm for patients with cirrhosis. Hepatology. 2012;56:1983-1992.

2. Tripodi A. Liver disease and hemostatic (Dys) function. Semin Thromb Hemost. 2015;41:462-467.

3. Wanless IR, Wong F, Blendis LM, Greig P, Heathcote EJ, Levy G. Hepatic and portal vein thrombosis in cirrhosis: possible role in development of parenchymal extinction and portal hypertension. Hepatology. 1995;21:1238-1247.

4. Trautwein C, Friedman SL, Schuppan D, Pinzani M. Hepatic fibrosis: concept to treatment. J Hepatol. 2015;62:S15-24.

5. Villa E, Camma C, Marietta M, et al. Enoxaparin prevents portal vein thrombosis and liver decompensation in patients with advanced cirrhosis. Gastroenterology. 2012;143:1253-1260.

6. Hochart H, Jenkins PV, Smith OP, White B. Low- molecular weight and unfractionated heparins induce a downregulation of inflammation: decreased levels of proinflammatory cytokines and nuclear factor- kappaBin LPS- stimulated human monocytes. Br J Haematol. 2006;133:62-67.

7. Norrby K. Low- molecular- weight heparins and angiogenesis. APMIS. 2006;114:79-102.

8. Morrison AM, Wang P, Chaudry IH. A novel nonanticoagulant heparin prevents vascular endothelial cell dysfunction during hyperdynamic sepsis. Shock. 1996;6:46-51.

9. Shi J, Hao JH, Ren WH, Zhu JR. Effects of heparin on liver fibrosis in patients with chronic hepatitis B. World J Gastroenterol. 2003;9: 1611-1614.

10. Abdel-Salam OM, Baiuomy AR, Ameen A, Hassan NS. A study of unfractionated and low molecular weight heparins in a model of cholestatic liver injury in the rat. Pharmacol Res. 2005;51:59-67.

11. Abe W, Ikejima K, Lang T, et al. Low molecular weight heparin prevents hepatic fibrogenesis caused by carbon tetrachloride in the rat. J Hepatol. 2007;46:286-294.

Fortea, J. I.; Zipprich, A.; Fernandez-Mena, C.; Puerto, M.; Bosoi, C. R.; Almagro, J.; Hollenbach, M.; Bañares, J.; Rodríguez-Sánchez, B.; Cercenado, E.; Clément, M.-A.; Rose, C. F.; Bañares, R.; Vaquero, J. \& Ripoll, C. Enoxaparin does not ameliorate liver fibrosis or portal hypertension in rats with advanced cirrhosis. Liver international 2018, 38, 102-112 
This is the peer reviewed version of the following article: Fortea, J. I.; Zipprich, A.; Fernandez-Mena, C.; Puerto, M.; Bosoi, C. R.; Almagro, J.; Hollenbach, M.; Bañares, J.; Rodríguez-Sánchez, B.; Cercenado, E.; Clément, M.-A.; Rose, C. F.; Bañares, R.; Vaquero, J. \& Ripoll, C. Enoxaparin does not ameliorate liver fibrosis or portal hypertension in rats with advanced cirrhosis. Liver international 2018, $38,102-112$, which has been published in final form at 10.1111/liv.13510. This article may be used for non-commercial purposes in accordance with Wiley Terms and Conditions for Use of Self-Archived Versions.

12. Assy N, Hussein O, Khalil A, et al. The beneficial effect of aspirin and enoxaparin on fibrosis progression and regenerative activity in a rat model of cirrhosis. Dig Dis Sci. 2007;52:1187-1193

13. Kukner A, Tore F, Firat T, et al. The preventive effect of low molecular weight heparin on CCL(4)- induced necrosis and apoptosis in rat liver. Ann Hepatol. 2010;9:445-454.

14. Cerini F, Vilaseca M, Lafoz E, et al. Enoxaparin reduces hepatic vascular resistance and portal pressure in cirrhotic rats. J Hepatol. 2016;64:834-842.

15. Regimbeau JM, Fuks D, Kohneh-Shahri N, Terris B, Soubrane O. Restrictive model of compensated carbon tetrachlorideinduced cirrhosis in rats. World J Gastroenterol. 2008;14:6943-6947.

16. Bosoi CR, Parent-Robitaille C, Anderson K, Tremblay M, Rose CF. AST- 120 (spherical carbon adsorbent) lowers ammonia levels and attenuates brain edema in bile duct- ligated rats. Hepatology. 2011;53:1995-2002.

17. Loureiro-Silva MR, Iwakiri Y, Abraldes JG, Haq O, Groszmann RJ. Increased phosphodiesterase- 5 expression is involved in the decreased vasodilator response to nitric oxide in cirrhotic rat livers. J Hepatol. 2006;44:886-893.

18. Zipprich A, Loureiro-Silva MR, Jain D, D’Silva I, Groszmann RJ. Nitric oxide and vascular remodeling modulate hepatic arterial vascular resistance in the isolated perfused cirrhotic rat liver. J Hepatol. 2008;49:739-745.

19. Hiebert LM, Wice SM, McDuffie NM, Jaques LB. The heparin target organ-the endothelium. Studies in a rat model. Q J Med. 1993;86:341-348.

20. Upchurch GR Jr, Welch GN, Freedman JE, et al. High- dose heparin decreases nitric oxide production by cultured bovine endothelial cells. Circulation. 1997;95:2115-2121.

21. Bachetti T, Pasini E, Clini E, Cremona G, Ferrari R. High- dose heparin impairs nitric oxide pathway and vasomotion in rats. Circulation. 1999;99:2861-2863.

22. Horstman DJ, Fischer LG, Kouretas PC, Hannan RL, Rich GF. Role of nitric oxide in heparin- induced attenuation of hypoxic pulmonary vascular remodeling. J Appl Physiol. 1985;2002(92):2012-2018.

23. Tasatargil A, Ogutman C, Golbasi I, Karasu E, Dalaklioglu S. Comparison of the vasodilatory effect of nadroparin, enoxaparin, dalteparin, and unfractioned heparin in human internal mammary artery. J Cardiovasc Pharmacol. 2005;45:550-554.

24. Yokokawa K, Tahara H, Kohno M, Mandal AK, Yanagisawa M, Takeda T. Heparin regulates endothelin production through endothelium-derived nitric oxide in human endothelial cells. J Clin Invest. 1993;92:2080-2085.

25. Chen JH, Karlberg KE, Sylven C. Heparin and low molecular weight heparin but not hirudin stimulate platelet aggregation in whole blood from acetylsalicylic acid treated healthy volunteers. Thromb Res. 1991;63:319-329.

26. Theroux P, Waters D, Lam J, Juneau M, McCans J. Reactivation of unstable angina after the discontinuation of heparin. N Engl J Med. 1992;327:141-145.

Fortea, J. I.; Zipprich, A.; Fernandez-Mena, C.; Puerto, M.; Bosoi, C. R.; Almagro, J.; Hollenbach, M.; Bañares, J.; Rodríguez-Sánchez, B.; Cercenado, E.; Clément, M.-A.; Rose, C. F.; Bañares, R.; Vaquero, J. \& Ripoll, C. Enoxaparin does not ameliorate liver fibrosis or portal hypertension in rats with advanced cirrhosis. Liver international 2018, 38, 102-112 